\title{
About self-activated orange emission in $\mathrm{ZnO}$
}

\author{
I.V. Markevich, T.R. Stara, V.O. Bondarenko \\ V. Lashkaryov Institute of Semiconductor Physics, NAS of Ukraine, \\ 41, prospect Nauky, 03028 Kyiv, Ukraine; \\ Phone: +38(044)525-7234; e-mail: stara_t@ukr.net
}

\begin{abstract}
Nominally undoped $\mathrm{ZnO}$ ceramics were sintered in air and $\mathrm{N}_{2}$ flow at $1000{ }^{\circ} \mathrm{C}$. Room temperature photoluminescence (PL) spectra of the samples were measured and analyzed using Gaussian fitting. The self-activated orange PL band peaking at $610 \mathrm{~nm}$ was separated by Gaussian deconvolution. Based on the obtained results compared with some literature data, it has been concluded that the defects responsible for self-activated orange emission in $\mathrm{ZnO}$ are zinc vacancies.
\end{abstract}

Keywords: $\mathrm{ZnO}$ ceramics, photoluminescence.

Manuscript received 08.12.14; revised version received 17.02.15; accepted for publication 27.05.15; published online 08.06.15.

\section{Introduction}

Among numerous applications of zinc oxide in optoelectronics, development of light emitters is one of the most important. In fact, it was shown that $\mathrm{ZnO}$ single crystals, ceramics, films and nanostructures with both intense excitonic UV and bright defect-related visible emissions could be prepared [1,2]. Based on careful study for several decades, origin of the most of UV bands in $\mathrm{ZnO}$ has been established quite unambiguously. At the same time, the electron-hole transitions responsible for defect-related emission and the origin of emitting centers are thus far the matter of discussion.

In undoped $\mathrm{ZnO}$, defect-related emission is known to exhibit itself as a broad structureless green-orange band which is stated to consist of several overlapping ones $[1,2]$. However, the number of the components and their peak positions are still debated through the literature. The majority of investigators believe that, in undoped $\mathrm{ZnO}$, two bands are observed in green spectral range, one of which is related to native defects, while the other is caused by residual copper impurity $[1,2]$. Emission in the red spectral range which exhibited itself as a shoulder at the longwave side of orange emission $[3,4]$ or as a separate band peaked at about $700 \mathrm{~nm}$ [4-6] was also reported. In yellow-orange spectral region, intense impurity-related PL bands peaked at 600 and $570 \mathrm{~nm}$ were found to appear due to doping with $\mathrm{Li}$ and $\mathrm{Na}$ accordingly $[1,2,7]$. As for self-activated orange emission, various bands peaked at $570 \ldots 590 \mathrm{~nm}$ [9-12], $610 \mathrm{~nm}[8,9,12], 614 \mathrm{~nm}[3], 620 \ldots 630 \mathrm{~nm}[14,15]$ and $640 \mathrm{~nm}[9,13,15]$ have been reported. This variety is usually related to the creation of different defects depending on the preparation method and ambient gas used. However, one of the reasons of such a discrepancy can be the fact that peak positions of emission bands are often determined using Gaussian fitting procedure. At the same time, Gaussian deconvolution of a broad structureless band will be rather ambiguous, if the number and peak positions of components are completely indeterminate. More reliable results can be obtained when the positions of some of components are established. In the present work, photoluminescence (PL) spectra of undoped $\mathrm{ZnO}$ ceramics were analyzed by Gaussian fitting. Deconvolution was made taking into account the positions of self-activated and $\mathrm{Cu}$-related green bands determined experimentally, as well as the position of self-activated red band taken from the literature. 


\section{Experimental procedure}

The samples were formed of the mixture of $\mathrm{ZnO}$ (99.99\% purity) powder with distilled water, dried at room temperature, sintered for 3 hours at $1000{ }^{\circ} \mathrm{C}$ in air, $\mathrm{N}_{2}$ flow or $\mathrm{Zn}$ vapor and cooled with the furnace. In the latter case, the samples were located in a closed crucible with metallic zinc scraps and annealed in $\mathrm{N}_{2}$ flow. Several samples sintered in air were doped with $\mathrm{Cu}$ by adding $\mathrm{CuCl}_{2}$ aqueous solution to the initial mixture. Obtained ceramics were cut transversally and defectrelated PL spectra in $400 \ldots 800 \mathrm{~nm}$ spectral range were measured at room temperature from both the surface and bulk of the samples. Xe-lamp light passing through grating monochromator was used as the exciting source, the wavelength $360 \mathrm{~nm}$ being chosen for PL excitation.

\section{Results and discussion}

In undoped samples sintered in air or $\mathrm{N}_{2}$ flow, a broad green-orange PL band with a noticeable "tail" in the red spectral region was observed. This emission was well seen by naked eye, but its intensity was not too high (Fig. 1, curve 1). The samples sintered in $\mathrm{Zn}$ vapor exhibited very intense and comparatively narrow green PL band peaked at $515 \mathrm{~nm}$ (Fig. 1, curve 3). The green band with almost the same width, weaker intensity and peak position at $540 \mathrm{~nm}$ was demonstrated by the samples doped with $\mathrm{Cu}$ (Fig. 1, curve 2).

Surface and bulk PL spectra of ceramics sintered in air and $\mathrm{N}_{2}$ flow are plotted in Figs 2 and 3. One can see that the curves have different shape and peak positions. Deconvolution of these curves by Gaussian fitting testifies, however, that, after separation of two green bands peaked at 515 and $540 \mathrm{~nm}$ as well as the red band peaked at $700 \mathrm{~nm}$, the residual orange band with peak position $610 \mathrm{~nm}$ manifests itself in all cases. The contribution of this band to PL spectrum is more considerable in the samples sintered in $\mathrm{N}_{2}$ flow with respect to that sintered in air and its intensity is higher at the surface of the samples with respect to that in the bulk.

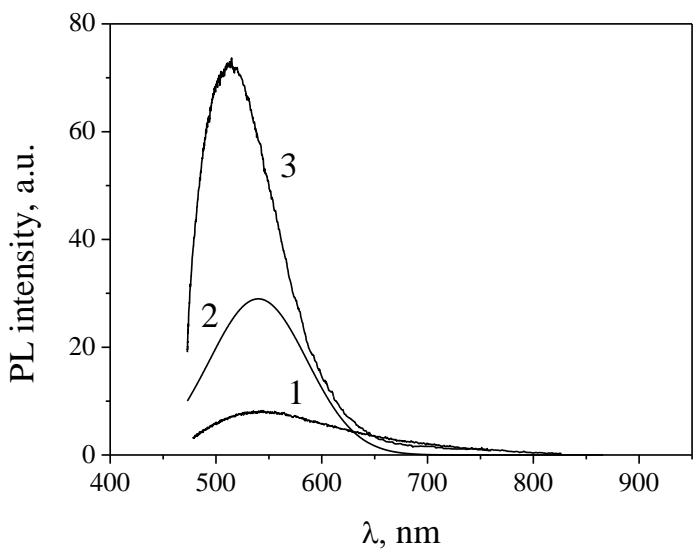

Fig. 1. PL spectra of $\mathrm{ZnO}$ ceramics sintered in air (1) undoped, (2) doped with $\mathrm{Cu}$ and (3) sintered in $\mathrm{Zn}$ vapor.
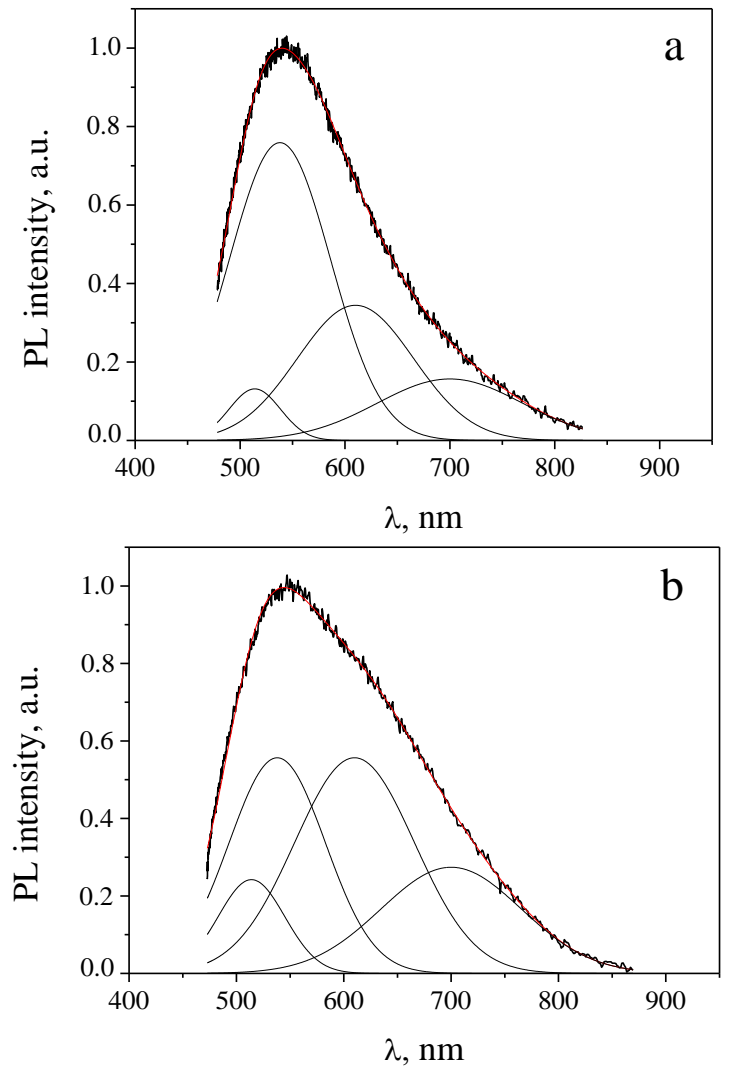

Fig. 2. $\mathrm{PL}$ spectra of undoped $\mathrm{ZnO}$ ceramics sintered in air: bulk (a) and surface (b) of the sample.
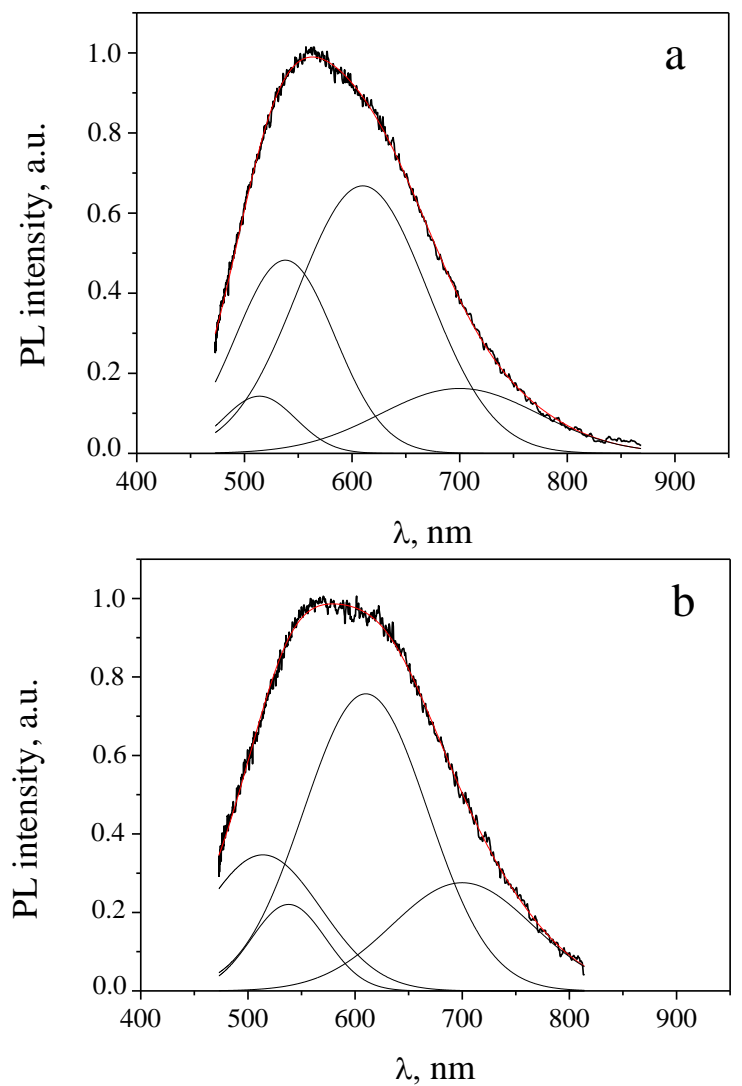

Fig. 3. PL spectra of undoped $\mathrm{ZnO}$ ceramics sintered in $\mathrm{N}_{2}$ flow: bulk (a) and surface (b) of the sample. 
The results of Gaussian deconvolution also show that self-activated green emission is the brightest one only in the samples sintered in $\mathrm{Zn}$ vapor, whereas in the samples sintered in air or $\mathrm{N}_{2}$ flow its intensity is rather low and $\mathrm{Cu}$-related band dominates in the green spectral region.

As literature survey has shown, orange emission in $\mathrm{ZnO}$ crystals, films, powders and nanostructures can be obtained by the annealing in air or oxygen ambient, and it is associated with stoichiometric oxygen excess in the form of oxygen interstitials [1-3, 9, 11-14, 16]. In [8], however, bright orange PL was obtained by annealing in vacuum of high-purity $\mathrm{ZnO}$ powder that demonstrated initially intense green PL band. With increasing the annealing temperature $T_{a n n}$ from 500 up to $800{ }^{\circ} \mathrm{C}$, gradual conversion of green band peaked at $515 \mathrm{~nm}$ into the orange one peaked at $610 \mathrm{~nm}$ was observed, a layer of metallic $\mathrm{Zn}$ being formed on the cold end of the silica tube in which the annealing was performed [8]. Based on these facts, it was stated that emitting centers responsible for orange PL were related to zinc vacancies $\mathrm{V}_{\mathrm{Zn}}$ created due to zinc evaporation [8]. The annealing of the same powder in air resulted in the appearance of both orange and red PL bands, which relative intensities were dependent on $T_{a n n}$ [4]. The red band arose at $T_{a n n}=450{ }^{\circ} \mathrm{C}$ and enhanced up to $T_{a n n}=600{ }^{\circ} \mathrm{C}$ as a separate band, then exhibited itself as a shoulder of growing orange band and at last hid in the tail of the latter at $T_{a n n} \geq 800{ }^{\circ} \mathrm{C}$ [4]. When the initial powder was annealed with $\mathrm{Cu}$ or $\mathrm{Fe}$ oxide, orange emission disappeared, and only the intense red PL band was observed [4]. This effect can be accounted for by the incorporation of impurity atoms into zinc vacancies, which is consistent with made in [8] conclusion about the origin of emitting centers responsible for selfactivated orange $\mathrm{PL}$ band in $\mathrm{ZnO}$.

Results obtained in the present work confirmed the role of zinc vacancies in formation of orange emission in intentionally undoped zinc oxide. In fact, one can expect that more intense $\mathrm{Zn}$ evaporation will occur, and the higher density of zinc vacancies will be created: i) on the surface of the sample than that in its bulk; ii) under annealing in $\mathrm{N}_{2}$ flow with respect to that in immobile air due to removal of evaporated $\mathrm{Zn}$ from annealing zone by gas stream. As Figs 2 and 3 show, contribution of the orange band to PL spectrum is greater on the surface of the samples than in their bulk and after annealing in $\mathrm{N}_{2}$ flow than in air, indeed. The other evidence of $\mathrm{Zn}$ removal from undoped ceramics under annealing is a low intensity of self-activated green emission that is associated with stoihiometric excess of zinc $[1,2,17]$.

\section{Conclusion}

In order to ascertain the position of self-activated orange emission in zinc oxide, surface and bulk PL spectra of nominally undoped $\mathrm{ZnO}$ ceramics sintered in air or $\mathrm{N}_{2}$ flow were measured and analyzed using
Gaussian fitting. Gaussian deconvolution was made using experimentally obtained positions of the selfactivated and $\mathrm{Cu}$-related green PL bands as well as the self-activated red PL band position taken from the literature. After such a procedure, the same orange PL band peaked at $610 \mathrm{~nm}$ was separated in all the PL spectra. The contribution of this band to PL spectra was found to be greater in the samples sintered in $\mathrm{N}_{2}$ flow than that in those sintered in air and for the surface of the samples with respect to their bulk. This effect was accounted for as caused by evaporation of zinc from the samples under annealing, which is confirmed by the weak self-activated green PL band related to stoichiometric $\mathrm{Zn}$ excess. The obtained results compared with some literature data led to the conclusion that native defects responsible for the self-activated orange band were zinc vacancies.

\section{Acknowledgement}

This research has been financially supported by National Academy of Sciences of Ukraine (project III-4-11).

\section{References}

1. I. Kuzmina, V. Nikitenko, Zinc Oxide. Production and Optical Properties. Nauka, Moscow, 1984 (in Russian).

2. U. Ozgur, Ya.I. Alivov, C. Liu, A. Teke, M.A. Reshchikov, S. Dogan, V. Avrutin, S.-J. Cho, H. Morkos, A comprehensive review of $\mathrm{ZnO}$ materials and devices // Appl. Phys. Rev., J. Appl. Phys. 98, 041301 (1-102), (2005).

3. R.B. Lauer, The IR photoluminescence emission band in $\mathrm{ZnO} / /$ J. Phys. Chem. Sol. 34, p. 249-253 (1973).

4. Yu.M. Gerbshtein, Ya.M. Zelikin, About red luminescence band in zinc oxide // Optika $i$ Spektroskopiia, 28, p. 521-523(1970), in Russian.

5. V.A. Nikitenko, K.E. Tarkpea, A.S. Tereshchenko, I.P. Kuz'mina, Red luminescence of zinc oxide // Zhurnal Prikladnoi Spektroskopii, 51, p. 986-988 (1989), in Russian.

6. L.A. Kappers, O.R. Gilliam, S.M. Evans, L.E. Halliburton, N.C. Giles, EPR and optical study of oxygen and zinc vacancies in electron-irradiated $\mathrm{ZnO} / /$ Nucl. Instrum. Meth. 266, p. 2953-2957 (2008).

7. V.I. Kushnirenko, I.V. Markevich, T.V. Zashivailo, Acceptors related to group I elements in $\mathrm{ZnO}$ ceramics // J. Lumin. 132, p. 1953-1956 (2012).

8. Yu.M. Gerbshtein, Ya.M. Zelikin, About the origin of the centers of yellow-orange luminescence in zinc oxide // Optika i Spektroskopia, 27, p. 515-518 (1969), in Russian.

9. H.S. Kang, J.W. Kim, S.H. Lim, H.W. Chang, G.H. Kim, J.H. Kim, S.Ye. Lee, Investigation on the variation of green, yellow and orange emission 
properties of $\mathrm{ZnO}$ thin films // Superlatt. Microstructures, 39, p. 193-201 (2006).

10. M. Liu, A.H. Kitai, P. Mascher, Point defects and luminescence centers in zinc oxide and zinc oxide doped with manganese // J. Lumin. 54, p. 35-42 (1992).

11. Ch.H. Ahn, Y.Yi. Kim, D.Ch. Kim, S.K. Mohanta, H.K. Cho, A comparative analysis of deep level emission in $\mathrm{ZnO}$ layers deposited by various methods // J. Appl. Phys. 105, 013502 (1-5), (2009).

12. H.C. Ong, G.T. Du, The evolution of defect emissions in oxygen-deficient and -surplus $\mathrm{ZnO}$ thin films: the implication of different growth modes // J. Cryst. Growth, 265, p. 471-473 (2004).

13. E.S. Shim, H.S. Kang, S.S. Pang, J.S. Kang, I. Yun, S.Y. Lee, Annealing effect on the structural and optical properties of $\mathrm{ZnO}$ thin films on InP // Mat. Sci. Eng. B, 102, p. 366-369 (2003).
14. Z.W. Li, W. Gao, Growth of zinc oxide thin films and nanostructures by wet oxidation // Thin Solid Films, 515, p. 3323-3329 (2007).

15. S.A. Studenikin, N. Golego, M. Cocivera, Fabrication of green and orange photoluminescent undoped $\mathrm{ZnO}$ films using spray pyrolysis // J. Appl. Phys. 84, p. 2287-2294 (1998).

16. L. Cui, H.-Y. Zhang, G.G. Wang, F.-X. Yang, X.-P. Kuang, R.Sun, J.-C.Han, Effect of annealing temperature and annealing atmosphere on the structure and optical properties of $\mathrm{ZnO}$ thin films on sapphire (0001) substrates by magnetron sputtering // Appl. Surf. Sci. 258, p. 2479-2485 (2012).

17. N.O. Korsunska, L.V. Borkovska, B.M. Bulakh, L.Yu. Khomenkova, V.I. Kushnirenko, I.V. Markevich, The influence of defect drift in external electric field on green luminescence of $\mathrm{ZnO}$ single crystals // J. Lumin. 102-103, p. 733-736 (2003). 